\title{
QUAL O EFEITO DA AGRESSIVIDADE TRIBUTÁRIA NA RENTABILIDADE FUTURA? UMA ANÁLISE DAS COMPANHIAS ABERTAS BRASILEIRAS ${ }^{12}$
}

\author{
WHAT IS THE EFFECT OF TAX AGGRESSIVENESS IN FUTURE PROFITABILITY? \\ AN ANALYSIS OF BRAZILIAN OPEN COMPANIES
}

\author{
¿CUÁL ES EL EFECTO DE LA AGRESIVIDAD TRIBUTARIA EN LA \\ RENTABILIDAD FUTURA? UN ANÁLISIS DE LAS COMPAÑ́́AS ABIERTAS \\ BRASILEÑAS
}

\begin{abstract}
Antônio Lopo Martinez, Doutor em Controladoria e Contabilidade pela Universidade de São Paulo e Doutor em Administração - Fundação Getúlio Vargas - SP. Endereço Profissional: Fundação Instituto Capixaba de Pesquisas em Contabilidade, Economia e Finanças (Fucape Business School). Av. Fernando Ferrari, 1358 Boa Vista, 29075505 - Vitória, ES - Brasil. Telefone: (27) 40094444. Homepage: www.fucape.br. E-mail: lopo@fucape.br.
\end{abstract}

Ana Paula Gobbi Sales Reinders, Mestre em Ciências Contábeis. Endereço Profissional: Fundação Instituto Capixaba de Pesquisas em Contabilidade, Economia e Finanças (Fucape Business School). Av. Fernando Ferrari, 1358 Boa Vista, 29075505 - Vitória, ES - Brasil. Telefone: (27) 40094444. Homepage: www.fucape.br. E-mail: anapaulagobbi78@ gmail.com.

\section{RESUMO}

As empresas buscam a cada dia alcançar maior economia tributária através de planejamento tributário. Porém, existem questões que geram dúvidas em relação a efetividade desse planejamento tributário, tal como se essa economia fiscal agrega valor à firma. Em outras palavras, existe a possibilidade de uma rentabilidade maior na empresa quando ela paga menos imposto? Investigou-se esta questão testando planejamento tributário agressivo e a rentabilidade atual e futura nas empresas de capital aberto brasileiras no período de 2004 a 2013. Os resultados evidenciaram que as empresas menores são mais agressivas em termos tributários. No que toca ao efeito da agressividade tributária na rentabilidade futura não foi identificado uma relação significativa. A hipótese de que as empresas mais agressivas tributariamente tenderiam a ser mais rentável no futuro não foi confirmada nesta pesquisa. $\mathrm{Ou}$ seja, o estudo apresentado identificou não existir uma relação significativa entre agressividade tributária e rentabilidade futura. É provável, que as empresas no momento em que adotam práticas mais agressivas tributárias de planejamento fiscal, incorram numa série de custos não tributários, que acabam sendo iguais ou até superiores ao potencial ganho decorrente da economia fiscal nos tributos explícitos.

Palavras-chave: Agressividade Tributária; Rentabilidade; Taxa de Tributação Efetiva.

\footnotetext{
${ }^{1}$ Artigo submetido em 28/11/2017, revisado em 08/02/2018, aceito em 01/03/2018 e divulgado em 10/07/2018 pelo Editor João Carlos Hipólito Bernardes do Nascimento, após double blind review.

${ }^{2}$ Artigo apresentado no X Congresso AnpCont (2016).

GєCont, v. 5, n. 1, Floriano-PI, Jan-Jun. 2018.
} 


\begin{abstract}
Companies seek every day to achieve more tax savings through tax planning. However, there are issues that generate doubts about the effectiveness of this tax planning, as this tax economy adds value to the firm. In other words, there is a possibility of increased profitability in the company when it pays less tax? We investigated this question by testing aggressive tax planning and the current and future profitability in Brazilian public companies from 2004 to 2013. The results showed that smaller companies are more aggressive in tax terms. Regarding the effect of the tax aggression on future profitability a significant relationship was not identified. The hypothesis that the more tax aggressive companies tend to be more profitable in the future has not been confirmed in this study. That is, the presented study found there is no significant relationship between tax aggressiveness and future profitability. It is likely that the companies at the time they adopt more aggressive tax practices of tax planning, incurred a number of non-tax costs, which end up being equal to or greater than the potential gain from the tax savings in explicit taxes.
\end{abstract}

Keywords: Tax Aggressiveness; Profitability; Effective Tax Rate.

\title{
RESUMÉN
}

Las empresas buscan cada día alcanzar mayor economía tributaria a través de la planificación tributaria. Sin embargo, existen cuestiones que generan dudas en relación a la efectividad de esa planificación tributaria, tal como si esa economía fiscal agrega valor a la firma. ¿En otras palabras, existe la posibilidad de una mayor rentabilidad en la empresa cuando paga menos impuestos? Se investigó esta cuestión probando planificación tributaria agresiva y la rentabilidad actual y futura en las empresas de capital abierto brasileñas en el período de 2004 a 2013. Los resultados evidenciaron que las empresas menores son más agresivas en términos tributarios. En lo que se refiere al efecto de la agresividad tributaria en la rentabilidad futura no se identificó una relación significativa. La hipótesis de que las empresas más agresivas tributariamente tenderían a ser más rentables en el futuro no fue confirmada en esta investigación. Es decir, el estudio presentado identificó no existir una relación significativa entre agresividad tributaria y rentabilidad futura. Es probable que las empresas en el momento en que adopten prácticas más agresivas tributarias de planificación fiscal, incurran en una serie de costos no tributarios, que acaban siendo igual o hasta superiores al potencial ganadero derivado de la economía fiscal en los tributos explícitos.

Palabras clave: Agresividad Tributaria; la rentabilidad; Tasa de Tributación Efectiva.

\section{INTRODUÇÃO}

\subsection{Contextualização do tema}

T Tá alguns anos vem se intensificando as pesquisas sobre agressividade tributaria. No Brasil, as pesquisas ainda são escassas, entanto, dentre as que foram feitas, nenhuma evidencia se uma empresa ao adotar um comportamento agressivo, conseguirá um benefício futuro no resultado da empresa (MARTINEZ, 2017). O objetivo deste trabalho é avaliar os efeitos que o planejamento tributário agressivo tem sobre a rentabilidade futura das empresas brasileiras negociadas na Bovespa.

Os tributos foram criados para garantir as necessidades e os direitos da sociedade (GRECO, 2008); é um produto de interações entre diversos agentes econômicos da sociedade nos quais o governo e as empresas estão inseridas (CABELLO, 2012, p. 5). É notório que os 
indivíduos procuram agir em função dos seus próprios interesses pessoais, maximizando seu bem-estar e, por consequência, utilizando preferências por determinadas práticas contábeis. Para Greco (2008, p. 117), planejamento tributário é um conjunto de condutas que o contribuinte pode realizar visando à busca por uma carga tributária menor, legalmente possível (ARAUJO; LEITE FILHO, 2017).

Um planejamento tributário agressivo é uma forma de pagar menos impostos em que as empresas ingressam com uma ação que não está claramente estabelecido em lei, apenas em interpretações, levando-se em consideração o Código Tributário Nacional e a Constituição Federal. Neste caso, o contribuinte não ingressa com ação judicial, ele faz a escolha, realiza o procedimento e aguarda a resposta das autoridades fiscais (PACHECO, 2013).

Um bom planejamento tributário deve levar em consideração todas as partes, todos os tributos e todos os custos. Shackelford e Shevlin (2001 p. 323) apontam esses três temas na estrutura conceitual da gestão tributária: todas as partes, todos os tributos e todos os custos (all parties, all taxes, all costs). "Todas as partes" significa considerar as incidências tributárias em todas as partes envolvidas nas transações da empresa. "Todos os tributos" mostra que devem ser considerados não somente os tributos explícitos, mas também os implícitos e, "todos os custos", alerta que os tributos também representam custos e, portanto, devem ser considerados no processo de gestão tributária, pois a reestruturação da empresa para pagar menos tributos pode ser dispendiosa (SHACKEFORD; SHELVLIN, 2001).

Wilson (2009), Koester (2011), e Blaylock, Shevlin e Wilson (2012), evidenciam em seus estudos que planejamentos tributários agressivos afetam ganhos futuros, sendo consistente com a visão de que um importante objetivo de pesquisas em contabilidade é descobrir como as informações do balanço financeiro afetam os ganhos futuros. Katz et al. (2013), avaliaram como planejamentos tributários moderam a associação entre os componentes de rentabilidade atual e futura em cenários diferentes: existência de operações no exterior, estrutura de governança, transparência do ambiente de informação, liderança de mercado e estágio do ciclo de vida da empresa.

Os índices de desempenho do passado e do presente de uma empresa fornecem um alicerce para a previsão do desempenho futuro (PALEPU; HEALY, 2007). A rentabilidade é uma dessas medidas. Brigham e Houston (2001, p. 89) conceituam que rentabilidade é o resultado de uma série de políticas e decisões referentes à empresa, uma vez que mostra os efeitos combinados da liquidez, da gestão de ativos e do endividamento sobre resultados operacionais. Segundo Ross, Westield e Jaffe (2002, p. 49), uma empresa é considerada rentável, no sentido econômico, apenas quando a sua rentabilidade é maior do que aquela que os investidores podem obter nos mercados de capitais.

Existem diversas maneiras de analisar a rentabilidade de uma empresa. Matarazzo (2008, p. 397) destaca o retorno sobre os ativos, custo da dívida e retorno sobre o patrimônio líquido e, salienta que o objetivo destas medidas de rentabilidade é mensurar o grau de êxito econômico da empresa. Planejamento tributário é saúde para o bolso, pois representa maior capitalização do negócio, possibilidade de menores preços e ainda facilita a geração de novos empregos, pois os recursos economizados poderão possibilitar novos investimentos (ZANLUCA, 2012).

Para ajudar compreender melhor os mecanismos subjacentes a associação entre planejamento tributário e valor da firma, será examinado as implicações do planejamento tributário para rentabilidade futura usando as análises DuPont. O padrão da análise DuPont decompõe retorno sobre o patrimônio (ROE) em três componentes, margem de lucro operacional líquida, volume de negócios líquido de ativos operacionais e o efeito de alavancagem.

O principal motivo desta pesquisa é avaliar os efeitos que o planejamento tributário tem sobre a rentabilidade atual e futura das empresas abertas brasileiras. Espera-se que as 
empresas mais agressivas tributariamente tenham uma rentabilidade futura maior em relação à rentabilidade atual.

A questão de pesquisa que surge é: a agressividade tributária hoje leva as empresas a terem uma rentabilidade maior no futuro?

Considera-se, neste estudo, as seguintes hipóteses:

H1: Agressividade tributária influencia na rentabilidade atual e futura

H2: Agressividade tributária não influencia na rentabilidade atual e futura

Ao decorrer deste trabalho pretendeu-se:

a. Delinear a classificação das empresas abertas brasileiras em agressivas tributariamente e menos agressivas tributariamente;

b. Identificar as diferenças na rentabilidade entre as empresas brasileiras que fazem planejamento tributário agressivo quando comparadas às que não são;

c. Validar o modelo de Katz et al (2013) que relaciona o planejamento tributário agressivo com a rentabilidade futura;

d. Investigar o efeito que o planejamento tributário agressivo tem sobre a rentabilidade futura nas empresas abertas brasileiras.

O trabalho está dividido em 5 partes. O primeiro trata da presente introdução. Na parte 2 é abordado o referencial teórico, o qual apresenta os conceitos fundamentais e estudos realizados no tema em questão. Na parte 3 apresenta-se a metodologia empregada no estudo e, na parte 4, as análises e discussões dos resultados. E, finalmente, na parte 5 as conclusões.

\section{REVISÃO DA LITERATURA}

As atividades de planejamento tributário são elaboradas com a finalidade de fazer uma economia legal na redução da carga tributária da empresa. Pode-se classificar a gestão tributária em três graus: planejamento tributário conservador, moderado ou agressivo. A decisão em assumir riscos maiores ou menores na hora de pagar mais ou menos impostos depende do gestor. Ao escolher a forma, assumem-se riscos calculados evitando a sonegação fiscal.

Segundo Chaves (2014), planejamento tributário conservador é aquele procedimento que consta na lei ordinária, dispensando qualquer interpretação jurídica, aplicações de princípios ou conhecimento da Constituição Federal ou Código Tributário Nacional. No planejamento tributário moderado, o contribuinte precisa ter conhecimentos da legislação tributária, da Constituição Federal e do Código Tributário Nacional, além de acompanhar os posicionamentos do Poder Judiciário. Neste grau, o contribuinte deve fazer consultas aos órgãos competentes ou ingressar com ação no Poder Judiciário, antes de fazer alguma mudança em seus procedimentos contábeis e fiscais.

Já no planejamento tributário agressivo, Chaves (2014) define que o contribuinte escolhe uma ação que não está prevista em lei, somente com base na interpretação da Constituição Federal e do Código Tributário Nacional. Não faz nenhuma consulta, aplica-se o que considera correto e espera-se a interpelação das autoridades fiscais. Mesmo a empresa sendo muito agressiva, ela está agindo de acordo com interpretações, correndo menos riscos que realizando a sonegação fiscal. Neste estudo, a exemplo de Katz et al. (2013), será investigado se essa economia tributária agressiva agrega valor à empresa. Estudos recentes evidenciam que as atividades de planejamento tributário aumentam os fluxos de caixa após os impostos (WILSON, 2009). Alguns pesquisadores como Lisowsky, Robinson e Schmidt 
(2013) consideraram, em um estudo com empresas americanas, que a operação média de isenção de imposto gera uma economia muito grande.

Desai e Dharmapala (2009), Wilson (2009), e Koester (2011) encontraram evidências de que os investidores valorizam positivamente diferentes graus de planejamento tributário, mas apenas em empresas bem governadas. Mas em contraste, Blaylock, Shevlin e Wilson (2012) documentam que planejamento tributário é geralmente associado positivamente com desempenho relativo futuro, mesmo em empresas mal governadas. Outro ponto refere-se às divulgações. Robinson e Schmidt (2012) encontraram a qualidade moderada de divulgações e a positiva associação entre retornos e benefícios fiscais incertos. Os investidores valorizam o planejamento tributário positivamente quando os gerentes o mascaram através de pobre divulgação. Hanlon e Slemrod (2009) encontraram que o mercado reage negativamente e pressiona as contas de participação de isenção fiscal.

Beaver (1998) fornece um elo teórico entre ganhos e valor da empresa argumentando que rentabilidade e ganhos atuais, fornecem informações para predizer ganhos futuros. Ou e Penman (1989), Lev e Thiagarajan (1993), e Abarbanel e Bushee (1997) utilizaram rateios financeiros para estimar "futuro poder de ganho" de empresas e estimar a associação entre informações contábeis e futuros retornos de ações. Nissim e Penman (2001) decompõe ROA em margem de lucro operacional líquida, volume de negócios líquido de ativos operacionais (NOAT) , alavancagem do passivo operacional (OLLEV) e os componentes de cada uma dessas relações. A margem de lucro operacional líquida (NOPM) fornece idéias sobre a sensibilidade do lucro operacional para o preço do produto e a estrutura do custo e, muitas vezes, é o resultado de poder de precificação de uma empresa.

NOAT, volume de negócios líquidos de ativos operacionais é uma medida de utilização de ativos e captura a eficiência da empresa em empregar ativos operacionais para gerar vendas. A alavancagem do passivo operacional (OLLEV) captura a alavancagem devida para passivos operacionais, por exemplo, os fornecedores geralmente cobram um preço mais elevado para as empresas que compram a crédito (Nissim e Peman, 2001). Soares e Galdi (2011) em sua pesquisa, analisaram o método DuPont explicando que o mesmo decompõe-se na fórmula comumente conhecida do ROE em três componentes básicos: margem de lucro, giro do ativo e o grau de alavancagem da empresa.

Katz et al. (2013) fizeram a associação entre ROA futura e NOPM (margem de lucro operacional líquida), NOAT (volume de negócios líquido de ativos operacionais) atual e OLLEV (alavancagem do passivo operacional) identificando as direções (caminhos) de rentabilidade futura para empresas que fazem planejamento tributário agressivo. Evidenciaram que as empresas com planejamento tributário agressivo têm significativamente um maior retorno antes dos impostos sobre o patrimônio líquido do que as empresas que não tem planejamento tributário agressivo. A principal causa, segundo eles, é a diferença na alavancagem financeira - empresas agressivas tributariamente têm significativamente mais dívida do que as empresas que não são.

Neste contexto, torna-se importante mencionar sobre a métrica ETR. Para Scholes e Wolfson (1992) a ETR (Effective Tax Rate) é uma taxa de despesa de impostos sobre a renda antes dos impostos da contabilidade financeira, em que a despesa do imposto de renda é uma estimativa da carga tributária real da empresa, levando em consideração as diferenças permanentes e temporárias entre o lucro financeiro e o lucro tributável.

Janssem (2000) expôs em sua pesquisa as razões pelas quais pesquisadores gostariam de conhecer o nível do ETR dentre elas que este indicador classifica as empresas que pagam mais e menos tributos. Segundo Cabello (2012) o montante de impostos pagos pelas empresas é a proxy para a mensuração da ETR e a comparação desta com a taxa de imposto. Para Hanlon e Heitzman (2010), existem diversas maneiras de calcular a ETR e que nem todas 
atendem às questões de pesquisas. Para elas ETR é um cálculo que divide alguma estimativa de imposto por uma medida de antes de impostos sobre os lucros ou sobre os fluxos de caixas.

A presente pesquisa utilizará a ETR, de acordo com a classificação de Hanlon e Heitzman (2010), mensurando a relação entre o Imposto de Renda e o Lucro antes do Imposto de Renda (LAIR). Para elas esta é a métrica utilizada que indica o grau do planejamento tributário agressivo das empresas. Desta forma, esperamos que a associação entre os componentes da rentabilidade atual e futura seja mais positivo para as empresas mais agressivas tributariamente do que para as demais empresas.

\section{METODOLOGIA}

\subsection{COLETA DOS DADOS}

Para realizar esta pesquisa, foram coletados no banco de dados da Economática os dados das empresas negociadas na Bovespa nos anos de 2004 a 2013. No caso de empresas com mais de um tipo de ação selecionou-se a que teve maior volume de negociação. Inicialmente a amostra foi composta por 727 empresas resultando em um total de 7270 observações. Algumas destas empresas não apresentaram dados para todos os anos deste estudo e, por isso, foram excluídas. Ao final do tratamento dos dados a amostra ficou composta por 204 empresas, num total de 2.040 observações.

\subsection{MODELO ECONOMÉTRICO}

A presente pesquisa utilizou-se da análise DuPont, o foco foi o ROA - retorno sobre os ativos operacionais líquidos, o qual ignora-se os efeitos da alavancagem financeira em rentabilidade futura. No caso em particular desta, assim como Katz et all (2008), foi utilizado a variável PTROA - Retorno dos Ativos antes dos impostos.

Para estabelecer as empresas mais agressivas tributariamente das demais, utilizou-se a métrica de ETR, definida pela a razão entre a soma dos dois últimos anos do Imposto de Renda e soma dos mesmos anos do LAIR.

Após os cálculos classificou-se as ETR em ordem decrescente, da maior para a menor. Dividiu-se a amostra em quartis. O primeiro quartil, ou seja, $25 \%$ das empresas que estiveram no grupo dos menores ETR são consideradas nesta amostra as empresas mais agressivas tributariamente e será atribuída a variável TAGG $=1$ (um). As demais empresas são consideradas nesta amostra, empresas menos agressivas tributariamente e recebem a variável TAGG $=0$ (zero).

Foram excluídas da coleta aquelas empresas que não apresentaram dados para todas as variáveis em todos os 10 períodos estudados, além disso, foram excluídas também, 1\% (um por cento) das empresas que apresentaram dados de ETR extremamente positivos e negativos, considerados outliers.

Uma vez as empresas classificadas, aplicou-se a equação lque irá indicar se existe uma relação entre agressividade e tamanho da empresa.

$$
\begin{aligned}
& T A G G_{i t}= \delta_{0} \\
&+\delta_{1} S_{I Z E_{i t}}+\delta_{2} S I Z E_{-} S Q_{i t}+\delta_{3} P_{T R O A_{i t}}+\delta_{4} P T R O A_{-} S Q_{i t} \\
&+\delta_{5} \text { LAG_CETR }_{i t}
\end{aligned}
$$

Em que a TAGG é uma variável que permite identificar as empresas que são mais agressivas tributariamente, ou seja, as que no grupo de análise apresentam o menor ETR, indicando que pagam menos tributos sobre os resultados. 
A variável SIZE é o Ativo Total, significando o tamanho da firma. Utilizamos o logaritmo de SIZE para que os dados possam ficar lineares; Size_SQ é o logaritmo do Ativo Total ao quadrado. PTROA (Retorno sobre os ativos antes do Imposto de Renda) é o LAIR dividido pelo Ativo Total. LAG_CETR é razão dos impostos pagos antes dos impostos no ano anterior ao exercício dividido pelo lucro antes do imposto de renda (LAIR) do mesmo ano.

Para investigar se existe uma relação significativa entre agressividade tributária e rentabilidade futura, a exemplo da pesquisa de Katz et al. (2013), aplicou-se a equação 2:

$$
\operatorname{PTROA}_{t+1}=\varphi_{0}+\varphi_{1} \text { PTROA }_{t}+\varphi_{2} \text { TAGG }_{t}+\varphi_{3} \text { PTROA }_{t} * T A G G_{t}
$$

Em que a PTROA é o retorno dos ativos antes dos impostos; a TAGG é a variável de agressividade tributária e, a variável PTROA * TAGG, é a interação entre rentabilidade e agressividade tributária.

\section{RESULTADOS E ANÁLISES DOS DADOS}

\subsection{ESTATÍSTICA DESCRITIVA}

Após todos os tratamentos dos dados pertinentes para esta pesquisa, foi realizada a análise descritiva da variável SIZE, indicativa de tamanho, conforme Tabela 1.

Tabela 1: Estatística Descritiva: 2004 a 2013

\begin{tabular}{|c|c|c|c|c|c|c|c|c|}
\hline \multicolumn{4}{|c|}{ TAGG=1 $(n=510)$} & \multicolumn{5}{|c|}{ TAGG $=0(n=1530)$} \\
\hline Variável & Média & Mediana & Q1 & Variável & Média & Mediana & Q1 & Dif. Média \\
\hline Size & 4,6204 & 5,1930 & 3,70423 & Size & 6,1501 & 6,3109 & 5,5164 & $-1,5296 * *$ \\
\hline
\end{tabular}

Nota: SIZE é o logaritmo de Ativo Total, ** Diferença significativa ao nível de $95 \%$

Como a variável SIZE é uma indicadora de tamanho, pois representa o Ativo Total, torna-se pertinente avaliar se os resultados demonstram que o tamanho da firma tem influência na agressividade tributária ou não.

Os resultados sugerem que as empresas menores são mais agressivas tributariamente e que as empresas maiores são menos agressivas tributariamente. A diferença das médias nos confirma a afirmação acima. À medida que as empresas da amostra se tornam maiores, a agressividade diminui.

\subsection{ANÁLISE DAS REGRESSÕES}

Foram rodadas as regressões das equações 1 e 2 constantes nas tabelas 2 e 3 respectivamente, através do Programa Eviews, o qual nos forneceu os resultados abaixo. 
Tabela 2: Regressão da Variável Dependente TAGG

\begin{tabular}{l|c|c|c|c}
\hline \multicolumn{1}{c|}{ Variável } & Coeficiente & Std. Erro & Estat. T & Probabilidade \\
\hline C & 0.623 & 0.128 & 4.861 & 0.0000 \\
SIZE & -0.107 & 0.051 & -2.094 & 0.0364 \\
SIZE_SQ & 0.008 & 0.006 & 1.419 & 0.1560 \\
PTROA & -0.0005 & 0.0004 & -1.083 & 0.2788 \\
PTROA_SQ & $1.52 \mathrm{E}-07$ & $2.19 \mathrm{E}-07$ & 0.694 & 0.4873 \\
LAG_CETR & -0.281891 & 0.0170 & -1.654 & 0.0000 \\
\hline
\end{tabular}

Nota: 2.040 observações. SIZE é o logaritmo de Ativo Total. SIZE_SQ é o logaritmo do Ativo Total ao quadrado. PTROA (Retorno sobre os ativos antes do Imposto de Renda) é o LAIR dividido pelo Ativo Total. PTROA_SQ é o PTROA ao quadrado. LAG_CETR é razão dos impostos pagos antes dos impostos no ano anterior ao exercício dividido pelo lucro antes do imposto de renda (LAIR) do mesmo ano.

A regressão acima trata-se da variável TAGG que é uma regressão binária, onde são classificadas as empresas mais agressivas tributariamente $(\mathrm{TAGG}=1)$ e menos agressivas tributariamente $(\mathrm{TAGG}=0)$. Os dados apresentaram que a variável indicadora de agressividade - LAG_CETR, apresentou-se significativa, porém negativa, assim como a variável indicadora de Tamanho - SIZE, significando que há uma tendência de que as empresas que foram mais agressivas tributariamente no presente, tenderão a ser agressivas no período subseqüente e, as menos agressivas, tenderão a continuar sendo menos agressivas tributariamente. $\mathrm{O}$ tamanho da empresa evidência que quanto menor a empresa mais agressiva ela tende a ser. Constata-se, portanto, uma persistência no tocante a agressividade fiscal.

Tabela 3: Regressão da Variável Dependente PTROA PA+1 $_{t}$

\begin{tabular}{l|c|c|c|c}
\hline \multicolumn{1}{c|}{ Variável } & Coeficiente & Std. Erro & Estat. T & Probabilidade \\
\hline C & 2.164 & 1.740 & 1.243 & 0.2139 \\
PTROA & 0.1613 & 0.024 & 6.556 & 0.0000 \\
TAGG & -4.364 & 4.835 & -0.902 & 0.3669 \\
PTROA*TAGG & -0.185 & 0.259 & 0.713 & 0.4754 \\
\hline
\end{tabular}

Nota: 2.040 observações. PTROA (Retorno sobre os ativos antes do Imposto de Renda) é o LAIR dividido pelo Ativo Total. TAGG é uma variável que permite identificar as empresas que são mais agressivas tributariamente, (1, para as mais agressisvas, 0 , não).

A regressão que trata das variáveis TAGG (agressividade tributária) e PRTOA (rentabilidade futura), forneceu resultados em que a variável PTROA (retorno do ativo antes dos impostos) apresentou-se significativa e com coeficiente positivo. Há, portanto, uma tendência de que as empresas mais agressivas possam ter um PTROA maior. Porém, a variável de agressividade - TAGG apresentou-se negativa indicando que nesta pesquisa ela não se mostrou estatisticamente significante. Já a variável de interação TAGG * PTROA, demonstrou que embora tenha encontrado um coeficiente negativo, que indicaria que as empresas mais agressivas seriam as mais rentáveis, apresentou-se com coeficiente não significativo.

\section{CONSIDERAÇÕES FINAIS}

Este estudo buscou evidenciar a relação entre agressividade tributária e rentabilidade futura nas empresas brasileiras listadas na Bovespa e com maior volume de negociação. As hipóteses foram testadas em uma amostra de 204 empresas coletadas no banco de dados da Economática, gerando um total de 2040 observações indústria/ano. Foram apresentadas as 
variáveis TAGG, uma variável de interação, além das variáveis SIZE, SIZE_SQ, PTROA, PTROA_SQ, LAG_CETR, ETR.

A partir dos resultados encontrados, evidenciou-se:

1) que empresas maiores tendem a ser menos agressivas tributariamente (Tabela 1) e empresas menores tendem a ser mais agressivas tributariamente.

2) há uma tendência, também, que as empresas que tenham LAG-CETR maiores sejam mais agressivas tributariamente no período subsequente e aquelas com LAG-CETR menores sejam menos agressivas tributariamente no período subsequente. Nota-se, portanto, uma persistência das empresas em seu comportamento.

3) a hipótese de que as empresas mais agressivas tributariamente tenderiam a ser mais rentável no futuro não foi confirmada nesta pesquisa. Ou seja, o estudo apresentado identificou não existir uma relação significativa entre agressividade tributária e rentabilidade futura, como a pesquisa feita lá fora.

Uma das implicações que poderiam ser analisada é em relação ao período de transição para a convergência às Normas Internacionais de Contabilidade, Lei 11.638/2007 que substituiu a Lei 6.404/76, bem como a instituição ao Regime Tributário de Transição (RTT) em 2008, onde alguns dos dados contábeis coletados nesta pesquisa podem ter sofrido com tais mudanças.

Conclui-se que há uma exigência de estudos mais aprofundados para investigar a relação entre agressividade tributária e rentabilidade futura. É provável, que as empresas no momento em que adotam práticas mais agressivas tributária de planejamento fiscal, incorram numa série de custos não tributários, que acabam sendo iguais ou até superiores ao potencial ganho decorrente da economia nos tributos explícitos. Por exemplo, é razoável supor que as empresas que sejam mais agressivas tributariamente incorram em maiores riscos de serem eventualmente questionadas em suas práticas fiscais pelas autoridades fiscais, resultando daí passivos fiscais e desgastes na imagem corporativa. De igual modo as empresas mais agressivas podem ser percebidas negativamente pelo mercado, sejam estes credores, pelos empregados e eventuais prestadores de serviço, que exigiram um sobre preço para prestar um serviço a determinada companhia.

Considerando que a pesquisa científica tem como objetivo contribuir para o esclarecimento do problema apresentado, é relevante mencionar possibilidades de futuras pesquisas pertinentes ao tema desenvolvido. Entre esses destacariam: i) avaliar a agressividade das empresas antes e depois da adoção das Normas Internacionais de Contabilidade e do Regime Tributário de Transição, bem como estabelecer se há uma relação com o retorno futuro. ii) promover pesquisas nas empresas mais agressivas tributariamente listadas na BM\&FBovespa, constatando se características tais como a estrutura da governança, liderança de mercado e ciclo de vida da empresa afetam o desempenho futuro, impactando na sua rentabilidade. iii) identificar potenciais custos não tributário nas empresas mais agressivamente em termos tributário, e verificando se os mesmos se equilibram ou até mesmo suplantam a economia de tributos explicita, promovida por práticas mais agressivas tributariamente.

É importante salientar que esta pesquisa espera ter contribuido para a divulgação de pesquisas na área tributária, além de levar o tema proposto à reflexão e debate sobre o perfil de agressividade tributária e o desempenho futuro das empresas. 


\section{REFERÊNCIAS}

ABARBANELL, J., BUSHEE, B.. Fundamental analysis, future earnings, and stock prices. Journal of Accounting Research, v. 35, n. 1, p. 1-24. 1997.

ARAÚJO, R. A. de M., LEITE FILHO, P. A. M. Análise da Relação entre o Nível de Agressividade Fiscal e a Rentabilidade das Empresas da BM\&FBovespa e NYSE. Apresentado na XI Congresso Anpcont, Belo Horizonte/MG. 2017.

BEAVER, W. Financial reporting: an accounting revolution. 3. ed. Upper Saddle, NJ: Prentice Hall. 1998.

BIBLIA, N. T. Bíblia sagrada. Reed. Versão de Anttonio Pereira de Figueiredo. São Paulo: Ed. Da Américas, 1950. Cap. 22, vers. 21. 1950

BLAYLOCK, B.; SHELVIN, T.; WILSON, R. Tax avoidance, large positive temporary book-tax differences, and earnings persistence. The Accounting Review, v. 87, n. 1, p. 91120. 2012

BRIGHAN, E. F.; HOUSTON, J. F. Fundamentals of financial management. 2. ed. Porto Alegre: Bookman. 2001

Cabelo, O. G. A análise dos efeitos das práticas de tributação do lucro na effective tax rate (ETR) das companhias abertas brasileiras: uma abordagem da teoria das escolhas contábeis. 2012. Tese (Doutorado em Ciências Contábeis) - Universidade de São Paulo (USP), São Paulo.

CHAVES, F. C. Planejamento Tributário na Prática: Gestão Tributária Aplicada. 3 ed. São Paulo: Atlas. 2014.

DESAI, M.; DHARMAPALA, D. Corporate tax avoidance and firm value. Review of Economics and Statistics, v. 91, n. 3, p. 537-546. 2009.

DESAI, M.; DYCK, A.; ZINGALES, L. Theft and taxes. Journal of Financial Economics, v. 84 , n. 3, p. 591-623. 2007

DESIONE, L.; STOMBERG, B. Do investors differentially value tax avoidance of income mobile firms? Working Papers Series. 2012. Disponível em:

<http://ssrn.com/abstract=2102903 or http://dx.doi.org/10.2139/ssrn.2102903>. Acesso em: 01 maio 2017.

GRECO, M. A. Planejamento tributário. 2. ed. São Paulo: Dialética. 2008.

HANLON, M.; SLEMROD, J. What does tax aggressiveness signal? Evidence from stock price reactions to news about tax shelter involvement. Journal of Public Economics, v. 93, n. 1-2, p. 126-141. 2009.

HANLON, M.; HEITZMAN, S. A review of tax research. Journal of Accounting and Economics, v. 50, n. 2-3, p. 127-178. 2010.

JANSSEN, B. Corporate effective tax rates in Netherlands. De Economist [S.1], v. 153, n.1, p.47-66. 2005.

KATZ, S.; KHAN, U.; SCHMIDT, A. P. Tax avoidance and future profitability. Working Paper, Columbia University, 2013. Disponível em: <http://ssrn.com/abstract=2227149 or http://dx.doi.org/10.2139/ssrn.2227149>. Acesso em: 30 maio 2017.

KÖCHE, J. C. Fundamentos da metodologia científica: teoria da ciência e prática da pesquisa. 15. ed. Petrópolis: Vozes. 1999. 
KOESTER, A. Investor valuation of tax avoidance through uncertain tax positions. Working Paper, Georgetown University. 2011.

KORMENDI, R.; LIPE, R. Earnings innovations, earnings persistence, and stock returns. Journal of Business, v. 60, p. 323-345. 1987.

LEONE, G. S. G.; LEONE, R. J. G. Dicionário de custos. São Paulo: Atlas. 2004.

Lev, B.; Thiagarajan, S. Fundamental information analysis. Journal of Accounting Research, v. 31, n. 2, p. 190-215. 1993.

LIPE, R. The information contained in the components of earnings. Journal of Accounting Research, v. 24, n. 1, p. 37-63. 1986.

LISOWSKY, P.; ROBINSON, L.; SCHIMIDT, A. Do publicly disclosed tax reserves tell usabout privately disclosed tax shelter activity? Journal of Accounting

Research,Forthcoming, v. 51, n. 3, p. 583-629. 2013.

MARTINEZ, A. L., Agressividade Tributária: um survey da literatura. Revista de Educação e Pesquisa em Contabilidade. V. 11, Edição Especial, p. 108-126, 2017.

MATARAZZO, D. C. Análise financeira de balanços. 6. ed. São Paulo: Atlas. 2008.

NISSIM, D.; PENMAN, S. Ratio analysis and equity valuation: from research to practice. Review of Accounting Studies, v. 6, p. 109-154. 2001.

OU, J.; PENMAN, S. Accounting measurement, P/E ratios and the information content of security prices. Journal of Accounting Research, v. 27, p. 111-144. 1989.

PACHECO, M. P. F. Transparência previne planejamento tributário agressivo. Consultor Jurídico. 2013. Disponível em: <http://www.conjur.com.br/2013-jul-11/mariana-pachecotransparencia-previne-planejamento-tributario-agressivo>. Acesso em: 01 maio 2016.

PALEPU, K. et al. Business analysis \& valuation: using financial statements. 3 ed. New Jersey: Thomson. 2004.

PALEPU, K. G.; HEALY, P. M., (2007). Business analysis and valuation tools. 4. ed. London: Cengage Learning. 2007.

REZENDE, J. A. et al. Contabilidade tributária: entendo a lógica dos tributos e seus reflexos sobre os resultados das empresas. São Paulo: Atlas. 2010.

ROBINSON, L.; SCHIMIDT, A. Firm and investor responses to uncertain tax benefit disclosure requirements. Working Paper, Dartmouth University and North Carolina State University. 2012

ROSS, S. A.; WESTERFIELD, R. W.; JAFFE, J. F. Corporate finance. 2. ed. São Paulo: Atlas, 2002.

SHACKELFORD, D. A.; SHEVLIN, T. J. Empirical tax research in accounting. Journal of Accounting \& Economics, v. 31, n 1-3. 2001

SOARES, E. R.; GALDI, F. C. Relação dos modelos DuPont com o retorno das ações no mercado brasileiro. Revista Contabilidade Financeira, São Paulo, v. 22, n. 57, p. 279-298. 2001.

WILSON, R. An examination of corporate tax shelter participants. The Accounting Review, v. 84, n. 3, p. 969-1000. 2009. 
ZANLUCA, J. C. Planejamento tributário: luxo ou necessidade? Portal Tributário. 2012. Disponível em: <http://www.portaltributario.com.br/artigos/planejamento.htm>. Acesso em: 30 maio 2017. 